\title{
Genetic diversity of Aspergillus flavus and occurrence of aflatoxin contamination in stored maize across three agro-ecological zones in Kenya
}

Grace W. Gachara', Anthony K. Nyamache ${ }^{2 *}$, Jagger Harvey ${ }^{3}$, Gbemenou J. B. Gnonlonfin ${ }^{3}$ and James Wainaina ${ }^{3}$

\begin{abstract}
Background: Aflatoxin contamination at pre- and post-harvest poses a serious challenge in achieving sustainable development goals on food security and food safety, in particular within the developing world. In Kenya, major outbreaks of aflatoxicoses have been reported and attributed to poor post-harvest storage practices. In this study, we conducted a cross-sectional survey within three Agro-ecological zones in Kenya, to determine occurrence and distribution of total aflatoxin in stored maize and the aflatoxigenicity potential of Aspergillus flavus in stored maize. The counties selected were: Kitui, Nakuru and Trans-Nzoia. Sampling sites were selected based on previous aflatoxicoses outbreaks (Kitui) and major maize production areas (Nakuru and Trans-Nzoia) where little information exists on the occurrence of aflatoxin contamination. One hundred and thirty (130) kernel maize samples were randomly collected. Aspergillus flavus was isolated by direct plating technique. Genetic diversity of the isolates was determined by PCR and single sequence repeats (SSR) microsatellites analysis. Positive strains were induced to produce $B_{1}$ aflatoxins on yeast extract sucrose agar and quantified using competitive ELISA technique.
\end{abstract}

Results: Total aflatoxin contamination of post-harvest stored maize samples between sites was significantly different $(p=0.000,<0.05)$, with the highest contamination in Kitale at a mean of $(9.68 \mu \mathrm{g} / \mathrm{kg})$. A. flavus was isolated in $70 \%$ $(N=91)$ of the maize samples collected at post-harvest. A. flavus isolates with the highest aflatoxigenicity potential were from Nakuru County with mean aflatoxin level at $239.7 \mu \mathrm{g} / \mathrm{kg}$. Genetic distance based on neighbor joining (NJ) clustered the A. flavus isolates into five main clusters including one clade with an admixture. Principal coordinate analysis showed five distinct clusters with both axes explaining $60.17 \%$ of the variance.

Conclusion: This study showed widespread distribution of aflatoxin contamination and a highly toxigenic A. flavus in stored maize in three major agro-ecological zones in Kenya. These results suggest a potential health risk of aflatoxin outbreaks under favorable conditions within these areas, thus calling for more investigations.

Keywords: Aspergillus flavus, Post-harvest period, Aflatoxin, SSR microsatellite markers, Kenya

\footnotetext{
*Correspondence: Nyamache.anthony@ku.ac.ke;

akibera2000@gmail.com

2 Department of Microbiology, Kenyatta University, P.O. Box 43844-00100,

Nairobi, Kenya

Full list of author information is available at the end of the article
} 


\section{Background}

Kenya, like most of the African countries, maize (Zea mays, $\mathrm{L}$ ), is one of the most important cereal, both as food and animal feed [1-3]. On average, $400 \mathrm{~g}$ of maize is consumed per day showing the levels high demand for this cereal in every home [4]. The main challenge of maize production and other cereals is susceptibility to aflatoxin contamination, which is a recurrent problem in several foodstuffs in Africa [4]. Mycotoxins are secondary metabolites produced by mycotoxigenic fungi, which are harmful to both humans and animals [5]. The most common mycotoxigenic fungi are Aspergillus, Fusarium and Penicillium that are found abundantly within humid areas [6]. Aspergillus flavus and Aspergillus parasiticus are ubiquitous and cosmopolitan fungi producing aflatoxins on a wide variety of substrates such as maize, peanut and cotton. Aspergillus flavus is a very important toxigenic fungus.

It produces aflatoxins that are toxic causing a serious health effects on humans and animals [7]. In subSaharan Africa, where most of the countries' climate is humid, farmers are therefore predisposed to high risk of aflatoxin contamination. In addition, excessive heat, lack of aeration in the storage area and lack of protection of maize stores against insects and rodents also lead to maize damage which contribute to huge economic losses [8]. The largest outbreak of aflatoxicoses to has been recorded in the world occurred in Western India in 1974 where 106 deaths and 397 cases were reported [9]. In Kenya, various cases of aflatoxin poisoning have been reported since 1981 [10] with high mortality rates being reported with children being the majority [11]. However, the highest reported aflatoxicosis outbreaks occurred in 2004 where 125 deaths and 317 cases were reported $[11,12]$.

In this study, we sought to determine the distribution and scope of the post-harvest contamination in stored maize in three agro-ecological zones in Kenya. In addition, genetic diversity of $A$. flavus and their toxigenicity potential was also determined.

\section{Methods}

\section{Survey sites and sample collection}

A cross-sectional survey was conducted on a total of 130 maize samples that were randomly sampled from three agro-ecological zones in Kenya. The survey sites included Kitui County in Eastern Kenya, a known hot spot for aflatoxicosis outbreaks, Nakuru County and Kitale District in Trans-Nzoia county which are known to be major maize producing areas in the country (Fig. 1).The maize samples had been stored for approximately $5-6$ months prior to the sampling period. The collected maize kernel samples were collected in sterile paper bags sealed and stored in less than $4{ }^{\circ} \mathrm{C}$.

\section{Determination of moisture content}

The moisture content for each sample was determined using the standard oven method [13]. The samples were first dried at $105{ }^{\circ} \mathrm{C}$ for $2 \mathrm{~h}$ to constant weight, and the mean moisture was calculated on percentage dry basis (Table 1).

\section{Fungal isolation}

Maize kernel surface was surfaced sterilized for $2 \mathrm{~min}$ in $10 \%$ sodium hypochlorite and washed in two changes of sterile distilled water and plated on potato dextrose agar (PDA). Plated kernels were incubated at $28 \pm 2{ }^{\circ} \mathrm{C}$ for 7 days (Samson et al, 2010). Fungal growth colonies on maize kernels were visualized using stereo-binocular microscope (Magnus M24), counted and identified based on their macroscopic and microscopic features [14], [15] .

\section{Aflatoxin analysis in collected maize samples}

Aflatoxin extraction and quantification were conducted through Vicam aflatest fluorometer method as previous described by Kana et al. [16]. The detection limit of the quantification method was $2.0 \mu \mathrm{g} / \mathrm{kg}$, and the upper limit was $300 \mu \mathrm{g} / \mathrm{kg}$. For samples above $300 \mu \mathrm{g} / \mathrm{kg}$, extracts were further diluted and additional $\times 5$ for an upper limit of $1500 \mu \mathrm{g} / \mathrm{kg}$.

\section{In vitro analysis of aflatoxin $\mathrm{B}_{1}$ from Aspergillus flavus isolates}

A total of ninety one (91) A. flavus isolates from the positive maize kernel samples were screened for aflatoxin production. Pure A. flavus isolates were inoculated in duplicate on aflatoxin inducing medium, yeast extract sucrose agar (YESA) and incubated in the dark for 7 days at $28 \pm 2{ }^{\circ} \mathrm{C}$. The aflatoxin $\mathrm{B}_{1}$ content in the medium was then analyzed using direct competitive ELISA as described by the manufacturer (Helica Biosystems, Fullerton, California).

\section{SSR genotyping of $A$. flavus isolates}

A. flavus isolates were sub-cultured in Malt Extract Agar (MEA) for three days and DNA extracted from young cultures using a modified CTAB protocol (Doyle and Doyle (1990). From the extracted DNA, a Singleplex PCR was conducted with different fluorescent labels [6-carboxyfluorescein, PET (applied biosystems), NED (applied biosystems), VIC (applied biosystem)] used in distinguishing the amplification products from each during co-loading stage of the markers. PCRbased SSR marker technology for characterizing Aspergillus flavus was adopted in this study. Fungal DNA was 


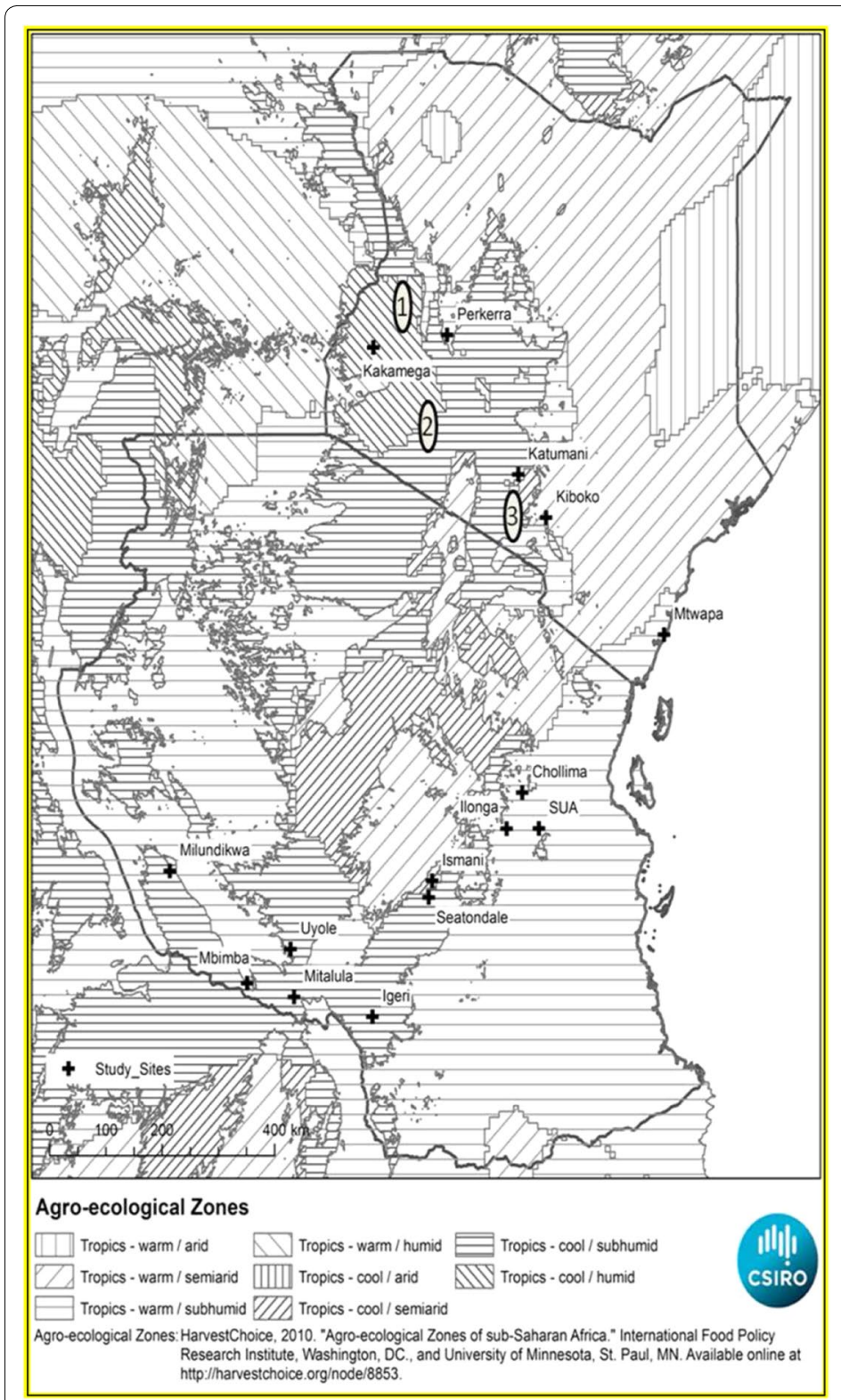

Key:

1-Kitale District in Trans-Nzoia County

2-Nakuru County

3-Kitui County

Fig. 1 Map of East Africa showing the three sampling locations. Map courtesy of IFPRI, Washington, DC and the University of Minnesota

Table 1 Moisture content levels of maize collected from three different geographical locations

\begin{tabular}{lllllrr}
\hline Sample site & AEZ & $\boldsymbol{N}$ & MC range & Samples $>$ 13\% & Samples $<\mathbf{1 3 \%}$ & Mean $(\%)^{*}$ \\
\hline Kitui & Semi-humid-semiarid & 30 & $13-25$ & 29 & 1 & $19.33^{\text {a }}$ \\
Kitale & Sub-humid-semi-humid & 40 & $6-34$ & 32 & 8 & $16.39^{\text {a }}$ \\
Nakuru & Semi-humid & 60 & $8-30$ & 50 & 10 & $17.23^{\text {a }}$ \\
\hline
\end{tabular}

$N$, sample size

*Means within a column with same superscripts are not significantly different $(p>0.05)$

amplified in a master mix constituting $10 \times$ buffer solution with of $20 \mathrm{mM} \mathrm{MgCl} 2,10 \mathrm{mM}$ dNTP mix, $5 \mathrm{pmol} /$ $\mu \mathrm{L}$ of forward and reverse primers ("Appendix"), $5 \mathrm{U} /$ $\mu \mathrm{L}$ Taq polymerase enzyme. PCR amplifications conditions were hot start at $94{ }^{\circ} \mathrm{C}$ for 5 min followed by 40 cycles of denaturation at $94{ }^{\circ} \mathrm{C}$ for $20 \mathrm{~s}$, annealing 
at $55{ }^{\circ} \mathrm{C}$ for $20 \mathrm{~s}$, and extension at $72{ }^{\circ} \mathrm{C}$ for $1 \mathrm{~min}$ and final extension at $72{ }^{\circ} \mathrm{C}$ for $30 \mathrm{~min}$. PCRs were run on Gene Amp PCR system 9700 (Perkin-Elmer, USA), and the amplifications were confirmed by visualization with GelRed staining of agarose gels and electrophoresis on a $2 \% \mathrm{w} / \mathrm{v}$ agarose gel (2 g agarose powder mixed with $200 \mathrm{ml}$ of TBE buffer) for $35 \mathrm{~min}$ at $100 \mathrm{~V}$.

For each sample, each fragment/band that was amplified using SSR primers was analyzed as a single locus in the haploid A. flavus genome. Positive Singleplex PCR products of the individual markers were co loaded based on the; (1) the fluorescence dye used and (2) PCR product size. Co-loading was carried out as; $1.5 \mu \mathrm{L}$ of the pooled PCR product mixed with $8.0 \mu \mathrm{L}$ of a cocktail of HIDI Formamide: GeneScan LIZ 500 (1:10) (applied biosystems). Denaturation was carried out at $95{ }^{\circ} \mathrm{C}$ for $5 \mathrm{~min}$ and subsequently chilled for an additional $5 \mathrm{~min}$. The PCR products were resolved by capillary electrophoresis ABI3730. The number of alleles per locus and haploid diversity were calculated using GenALex version 6.41 and Power marker v3.25 software [17]. Genetic distance matrix was used to perform principle coordinates analysis (PCA) and analysis of molecular variance (AMOVA) [18].

\section{Statistics}

Data were summarized and analyzed using SPSS (version 16.0.), and the Student Newman-Keul's test (SNK) and least significant differences (LSD) at $5 \%$ probability level were used to determine differences in the means among samples.

\section{Results}

Moisture content of stored maize

The percentage of moisture content differed across all the three sites; the widest range was from in Kitale samples, with as low as $6 \%$ and high of $34 \%$ (Table 1). Moisture content $(\mathrm{MC})$ within a majority of the samples $85 \%$ $(N=111)$ was above $13.5 \%$, the recommended safe storage level. Within the three sampling sites, samples with MC content of above $13.5 \%$ was highest in Nakuru $83 \%$ $(N=50)$ compared to Kitale $80 \%(N=32)$ and Kitui $3 \%$ $(N=1)$. Percentage moisture content between sites was, however, not significantly different $(p=0.23,>0.05)$.

\section{Mycoflora recovered from maize kernels collected at post-harvest}

A total of five fungal genera; Aspergillus, Penicillium, Fusarium, Rhizopus and Byssochlamys spp. were isolated from the analyzed maize samples. Other fungal genera recovered were: Cladosporium, Aureobasidium, Acremonium and Exophiala. Kitale had the highest levels of $A$. flavus isolates $(41 \%, N=40)$ followed by Nakuru (24\%, $N=60)$ and Kitui $(17 \%, N=30)$ as the least Aspergillus (51.91\%) and Fusarium (5.0\%) fungi were the most frequent isolated fungal genus with $A$. flavus (82.03\%) being most prevalent species (Fig. 2).

\section{In vitro toxigenicity of $A$. flavus isolates}

High levels of aflatoxin production were quantified from A. flavus isolates recovered from the analyzed maize samples. All A. flavus isolates from Kitui (30), Kitale (1) and

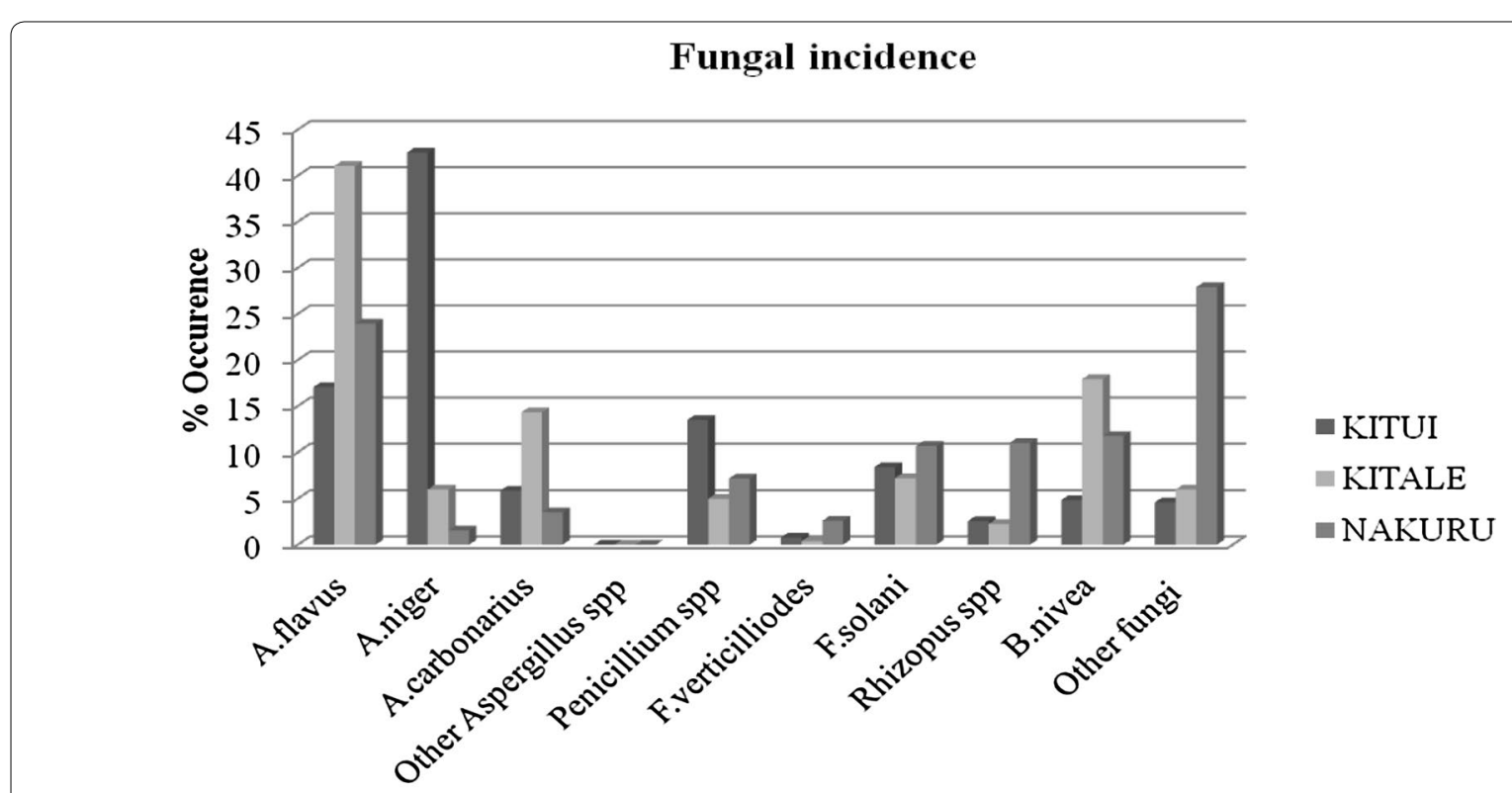

Fungal spp

Fig. 2 Frequency of isolation of fungi from maize kernels in three agro-ecological regions in Kenya 
Nakuru (32) produced high levels of aflatoxin $(219.2 \mu \mathrm{g} /$ $\mathrm{kg}),(234 \mu \mathrm{g} / \mathrm{kg})$ and $(239.7 \mu \mathrm{g} / \mathrm{kg})$, respectively (Fig. 3$)$.

\section{Aflatoxin contamination in the maize samples}

The levels of aflatoxin contamination in post-harvest maize samples varied across the study sites. In Kitale, aflatoxin contamination levels ranged between $<2 \mu \mathrm{g} /$ $\mathrm{kg}$ (undetectable levels) and $72 \mu \mathrm{g} / \mathrm{kg}$ with a mean of $9.70 \mu \mathrm{g} / \mathrm{kg}$. However, Kitale recorded the lowest mean at $0.68 \mu \mathrm{g} / \mathrm{kg}$ with Kitui having the highest mean at $4.18 \mu \mathrm{g} / \mathrm{kg}$. These two regions also recorded 3\% aflatoxin levels that were above $10 \mu \mathrm{g} / \mathrm{kg}$ (Table 2). Therefore, the significant difference $(p=0.00,<0.05)$ was observed between agro-ecological zones. Correlation between the incidence of $A$. flavus and aflatoxin levels in the analyzed maize samples was positive and significant $(r=0.85 ; p=0.01)$ across the sampling sites.

Genetic structure with $A$. flavus isolates from the three sites was determined using principal coordinate analysis (PCA) and neighbor joining dendrogram (Figs. 4, 5). PCA analysis based on the allele frequency of SSR showed five distinct clusters; the first axis 1 explained $35.86 \%$ of the variance with the axis 2 explaining $24.31 \%$ of variance. Admixture of $A$. flavus isolates was in clusters $\mathrm{A}, \mathrm{B} \mathrm{C}$ and $\mathrm{D}$ from isolates across the three sites Kitale, Kitui and Nakuru. Cluster E was composed of one distinct isolates (NAX 54) from Nakuru (Fig. 4). Further analysis based on the dendrogram (Fig. 5) showed five distinct clusters: Cluster one comprised of isolates from two geographical regions. Isolates from Nakuru formed the major part of this cluster with some Kitale isolates being spotted within this cluster. Cluster two also comprised mainly of Nakuru isolates with only one Kitui isolate (Kitui 6). Cluster three was a combination of isolates from all the three geographical locations in varied proportions. The most distinct cluster was cluster four that comprised of isolates exclusively from Nakuru with a few Kitui isolates

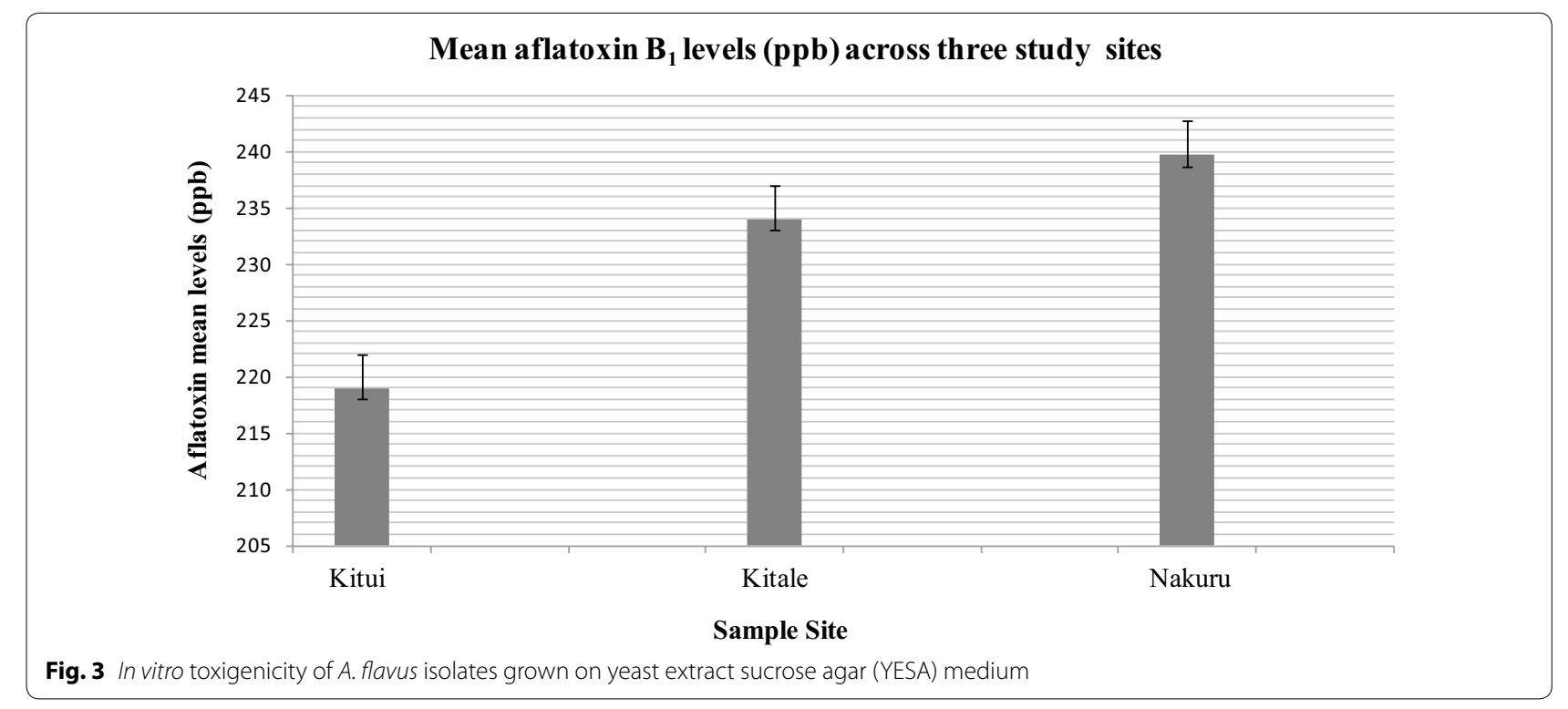

Table 2 Mean aflatoxin levels calculated on basis of the legal limit of $10 \mu \mathrm{gg} / \mathrm{kg}$

\begin{tabular}{|c|c|c|c|c|c|c|}
\hline Sample site & AEZ & $N$ & $\begin{array}{l}\text { Aflatoxin } \\
\text { contaminated } \\
\text { samples }\end{array}$ & Mean* $(\mu \mathrm{g} / \mathrm{kg})$ & $\begin{array}{l}\text { Range }(\mu \mathrm{g} / \mathrm{kg}) \\
(\min -\max )\end{array}$ & $\begin{array}{l}\text { Frequency } \\
\text { of contaminated } \\
\text { samples }\end{array}$ \\
\hline Kitui & Semi-humid-semiarid & 30 & 3 & $0.68^{\mathrm{a}}$ & $<2-13$ & $\begin{array}{l}<10 \mu \mathrm{gg} / \mathrm{kg} \text { 29/30 (97\%) } \\
>10 \mu \mathrm{g} / \mathrm{kg} 1 / 30(3 \%)\end{array}$ \\
\hline Kitale & Sub-humid-semi-humid & 40 & 23 & $9.70^{b}$ & $<2-72$ & $\begin{array}{l}<10 \mu \mathrm{g} / \mathrm{kg} 28 / 40(70 \%) \\
>10 \mu \mathrm{g} / \mathrm{kg} 12 / 40(30 \%)\end{array}$ \\
\hline Nakuru & Semi-humid & 60 & 50 & $4.20^{\mathrm{a}}$ & $<2-13$ & $\begin{array}{l}<10 \mu g / k g ~ 58 / 60(97 \%) \\
>10 \mu g / k g ~ 2 / 60(3 \%)\end{array}$ \\
\hline
\end{tabular}

$N$, sample size

*Means within a column with different superscripts are significantly different $(p<0.05$ 


\section{Principal Coordinates Analysis(PCA)}

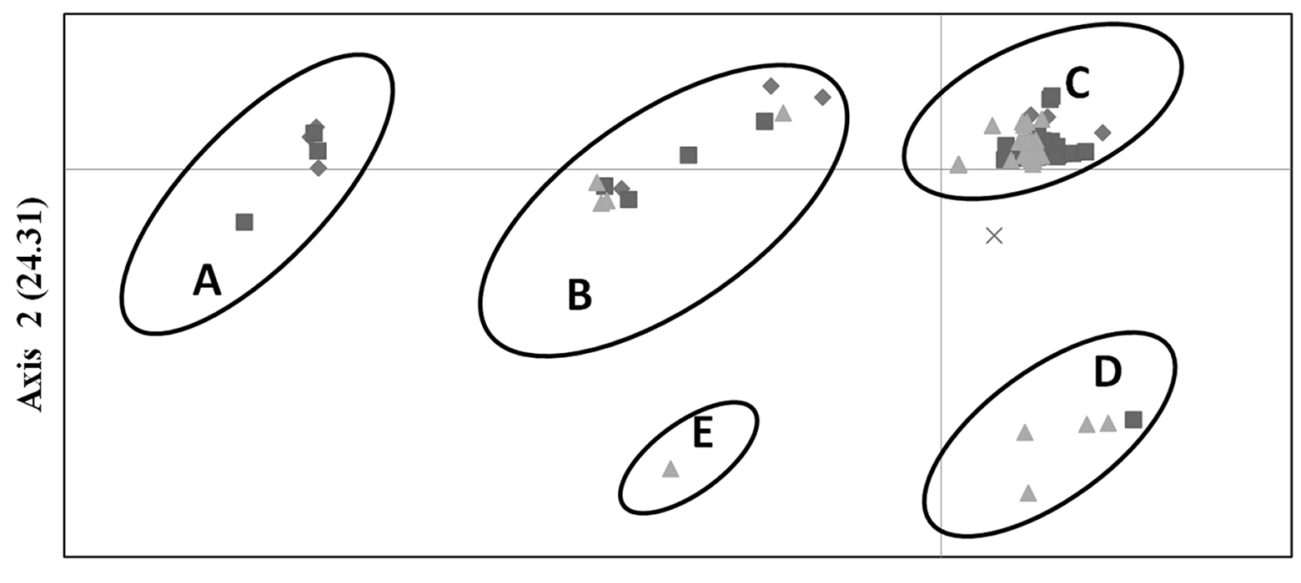

Axis 1(35.86)

- Kitui - Kitale $\triangle$ Nakuru $\times$ Cameroon

Fig. 4 Principal coordinates analysis (PCA) of 91 A. flavus isolates sampled from study sites

appearing toward the end of the cluster (Fig. 5). The final Cluster five also stood out with isolates only from Kitale region. Clustering within the dendrogram did not show correlation toward either geographical location or in vitro aflatoxin production potential.

\section{Informativeness of SSR markers used in the genetic diversity study}

SSR markers were used due their co dominant nature in distinguishing both homozygous and heterozygous alleles. The major allele frequency and gene diversity were ranged from 0.23 to 0.72 with a mean of 0.45 and 0.45 to 0.87 range with mean of 0.69 , respectively (Table 3 ). The heterozygosity ranged from 0 to 0.05 with a mean of 0.02 . The low heterozygosity mean value of 0.02 correlates to the haploid nature of the A. flavus fungus. Each SSR marker has an expected size range at which it is supposed to amplify. For all the 13 markers, amplification occurred at different positions. This was also confirmed after genotyping as shown by the different alleles at a given loci. The different alleles gave an allele frequency mean of 0.45 .

\section{Discussion}

This study provides the first snap shot of $A$. flavus genetic diversity from stored maize, the levels of toxins in the stored maize from different agro-ecological zones in Kenya. High moisture content above $13 \%$ has been found to favor fungal growth and mycotoxins development [8, 19]. This study measured moisture content, a key factor influencing aflatoxins production, and aflatoxin levels in three different ecological regions in Kenya. High variation in moisture content above recommended $13 \%$ by Food and Drug Administration regulatory guidance for stored maize was observed [20, 21]. However, there was no significant difference in the levels of moisture content across the regions (Table 1). These findings concur with previous studies that have been conducted in Kenya [22].

High moisture content of the maize kernels could be attributed to poor harvest practice or heavy rainfall during harvesting and inadequate drying. From the field observation, it was found that most farmers stored their maize using polystyrene bags placed directly on the floor that favor moisture development within the maize kernels. This study confirmed the fungal contamination of maize kernels with Aspergillus and Fusarium being the predominant fungi identified at frequency of 51.91 and 5\%, respectively (Fig. 2). Nevertheless, A. flavus was found to be the most predominant species, a finding that concurs with previous studies that have been conducted in Kenya and some countries in Africa [19, 23, 24].

Aspergillus and Fusarium are the dominant field fungi with their dominance at post-harvest indicative of preharvest contamination of the maize kernel, by the fungi occurring prior to storage. Thus, pre-harvest contamination of maize kernels directly influences mycobiota at post-harvest of maize kernel [25]. A. flavus the most dominant species (Fig. 2) could be attributed to the saprophytic nature of the fungus, its present in soils, and decaying plant material [26, 27]. Household farmers in Kenya harvest their maize and sun dry their produce 


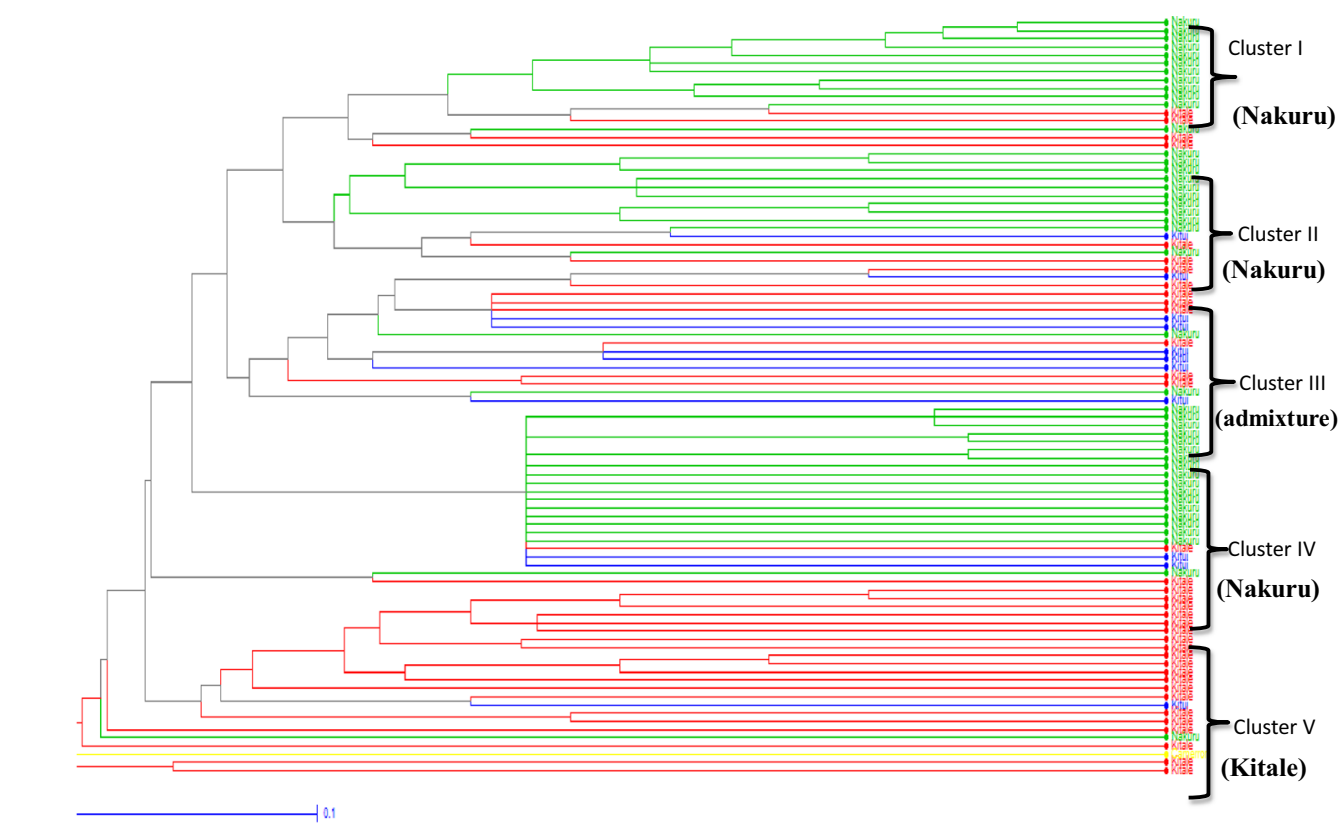

Key: sampled regions indicated by color of the nodes Kitale Kitui Nakuru

Fig. 5 Phylogenetic tree showing clustering of A. flavus genotypes generated based on 13 SSR markers using UPGMA pair wise genetic distance (Nei, 1972) with a bootstrap value of 100 replicates. The isolate form Cameroon was used as an outgroup to root the tree

directly on the ground, plastic or sisal gunny bags. Direct contact of maize kernels with soils increases the susceptibility of $A$. flavus colonization [28].

This could explain the high levels of $A$. flavus isolates across the three sites. Co-occurrence of mycotoxigenic fungi (Fusarium, Aspergillus and Penicillium) within maize kernels could indicate possibility of multiple toxins within the kernels. Further studies would, however, be required. In vitro assay using an aflatoxin inducing medium YESA has shown that most A. flavus isolates isolated in stored maize samples were toxigenic with significant amount of aflatoxin production (Fig. 2). Our findings concur with previous studies in Kenya that reported higher levels of toxigenicity A. flavus isolates compared to atoxigenic isolates, both in Eastern and Rift Valley [23, 29].

Similar results were reported in the southern USA $[26,30]$. However, our finding contradicts previous studies in Nigeria [28] and Argentina [31] where the atoxigenic $A$. flavus were majority. Modern agricultural practices have been implicated for development of an ecological niche responsible for the high toxigenic $A$. flavus isolates $[28,32]$ and having an inclination toward the high toxigenic isolates observed in Kenya. A. flavus isolates from Kenya have previously been described as distinctly different compared to other world strains and highly aflatoxigenic [29]. The levels of contamination of A. flavus were higher than the tolerance limit as given by the International Commission on Microbiological Specification for Food (ICMSF).

Aflatoxin levels in analyzed stored maize were above $10 \mu \mathrm{g} / \mathrm{kg}$, the legal limit (Table 2) and a positive and significant correlation was observed between $A$. flavus colonization and aflatoxin production $(p=0.01$, $r=0.85$ ). These findings are similar to previous studies in Kenya where high aflatoxin levels were reported in Eastern and Rift Valley [23], Kitui and Makueni regions [11]. Lewis and colleagues reported maize within Eastern province, as significantly more likely to have aflatoxin contamination compared to other regions in Kenya (odds ration $=2.71,95 \%$ ). Variation in aflatoxin contamination in maize within Kitui (Eastern Kenya) and Nakuru and Kitale (Rift Valley), could be explained by several factors; Nakuru and Kitale are major maize producers annual maize production is per acre at 25 bags [33]. Surplus amounts of maize within households lead to prolonged durations between harvest and consumption.

We hypothesis that the high aflatoxin levels in Kitale are attributed to a combination of factors. These could be the prolonged storage duration previously associated with an increase in aflatoxin contamination [34] coupled 
Table 3 Summary statistics showing the major allele frequency, allele number, gene diversity, heterozygosity and the polymorphism information content (PIC)

\begin{tabular}{llllll}
\hline Marker & $\begin{array}{l}\text { Major } \\
\text { allele } \\
\text { frequency }\end{array}$ & $\begin{array}{l}\text { Allele } \\
\text { no. }\end{array}$ & $\begin{array}{l}\text { Gene } \\
\text { diversity }\end{array}$ & Heterozygosity & PIC \\
\hline AF8 & 0.7079 & 11.0000 & 0.4795 & 0.0449 & 0.4600 \\
AF10 & 0.2838 & 15.0000 & 0.8616 & 0.0000 & 0.8500 \\
AF11 & 0.5167 & 10.0000 & 0.6939 & 0.0111 & 0.6718 \\
AF13 & 0.4615 & 7.0000 & 0.6690 & 0.0000 & 0.6153 \\
AF16 & 0.7267 & 9.0000 & 0.4533 & 0.0116 & 0.4335 \\
AF48 & 0.2963 & 13.0000 & 0.8134 & 0.0123 & 0.7908 \\
AF54 & 0.5893 & 9.0000 & 0.5709 & 0.0595 & 0.5136 \\
AF53 & 0.3767 & 8.0000 & 0.7396 & 0.0137 & 0.7005 \\
AF55 & 0.3614 & 10.0000 & 0.7783 & 0.0000 & 0.7499 \\
AF64 & 0.2381 & 16.0000 & 0.8790 & 0.0000 & 0.8686 \\
AF18 & 0.3077 & 12.0000 & 0.8327 & 0.0000 & 0.8149 \\
AF25 & 0.6463 & 10.0000 & 0.5581 & 0.0244 & 0.5375 \\
AF43 & 0.3750 & 8.0000 & 0.7491 & 0.0000 & 0.7111 \\
Mean & 0.4529 & 10.6154 & 0.6983 & 0.0137 & 0.6706 \\
\hline
\end{tabular}

with an aggressive aflatoxigenic A. flavus isolates and high $\mathrm{MC}$ of the stored maize kernels. We report for the first time the genetic diversity of $A$. flavus isolates from stored maize using eleven microsatellite (SSR) markers. All eleven SSR markers showed high level of polymorphism, with average polymorphism information content (PIC) as 0.67 , the lowest PIC being 0.46 and highest 0.86 (Table 3). The average number of alleles per locus ranged between seven and 16 per locus with an average of 10.6154. Possible explanation for higher genetic diversity within Kenyan isolates could be due to the high genetic recombination associated with A. flavus [35]. Comparison with previous studies using the same SSR markers by Grubisha and Cotty [36] indicated fewer alleles of between two and 19 across VCG; however, the A. flavus isolates they used were not from Kenya. The diversity study showed that $A$. flavus isolates were highly diverse across the agro-ecological zones but with no relation to geographical distance.

This findings correlate with findings by Wang et al. [37] and Geiser et al. [35] in the USA where there was lack of a distinct geographical patterns linked to A. flavus genotypes and aflatoxin production from various sources. The lack of distinct geographical pattern within A. flavus isolates could be attributed to narrow vegetative compatibility group (VCG) in circulation in Kenya, with similar dominant VCG in particular found within maize growing areas resulting to this niche. However, further studies would be required for confirmation since we did conduct VCG analysis on the isolated $A$. flavus isolates.

\section{Conclusion}

Findings from this study showed that maize stored in the sampled geographical regions were found to be highly contaminated. The level of extracted aflatoxins was found to be higher than the recommended level of $(10 \mu \mathrm{g} / \mathrm{kg})$. A. flavus strains were found to be the most predominant hence calling for adequate procedures that maintain low moisture content.

\begin{abstract}
Abbreviations
MC: moisture content; ICMSF: International Commission on Microbiological Specification for Food; PIC: polymorphism information content; PCA: principal coordinate analysis.

\section{Authors' contributions}

GWG conducted the mycological and genetic study tests and also took time to write the manuscript. AKN was the main supervisor who contributed a lot in giving guidance in the course of the study, editing the manuscript and coordinating all research activities. JH was the principal investigator who provided funding for the project through the ABCF fellowship program. GBG was the post-doctoral scientist who designed the study, supervised the laboratory experiments and availed the required reagents and equipment. JW helped with sample analysis, culturing of the isolates and statistical analysis. All authors read and approved the final manuscript.
\end{abstract}

\section{Author details}

1 Department of Public Health, Jomo Kenyatta University of Agriculture and Technology, P.O. Box 62,000-00200, Nairobi, Kenya. ${ }^{2}$ Department of Microbiology, Kenyatta University, P.O. Box 43844-00100, Nairobi, Kenya. ${ }^{3}$ Biosciences Eastern and Central Africa-International Livestock Research Institute (BecA-ILRI Hub), Nairobi, Kenya.

\section{Acknowledgements}

The authors would like to acknowledge Dr. Christopher Beadle and Dr. Peter Willadsen from Australia's Commonwealth Scientific and Industrial Research Organization (CSIRO), for their valuable training and assistance in preparation of this manuscript during the Scientific Research Paper Writing workshop held in Arusha, Tanzania.

\section{Competing interests}

The authors declare that they have no competing interests.

Availability of data and materials

All data generated or analyzed during this study are included in this published article (and its Appendix files).

\section{Consent for publication \\ Not applicable.}

Ethics approval and consent to participate

Ethics approval and consent to participate is not applicable in this study.

\section{Funding}

We gratefully acknowledge the financial support provided to the Bioscience eastern and central Africa Hub at the International Livestock Research Institute (BecA-ILRI Hub) by the Australian Agency for international Development (AusAID) through a partnership between Australia's commonwealth Scientific and Industrial Research Organization (CSIRO) and the BecA-ILRI Hub; and by Syngenta Foundation for Sustainable Agriculture (SFSA); the Bill \& Melinda Gates Foundation (BMGF); and the Swedish Ministry of Foreign Affairs through the Swedish International Development Agency (Sida), which made this work possible. 


\section{Appendix}

See Table 4.

Table 4 List of primers and their sequences that were used for PCR and genotyping

\begin{tabular}{|c|c|c|c|c|c|}
\hline Name of marker & Group no. & Primer sequence $\left(5^{\prime}-3^{\prime}\right)$ & Probe (DYE) & Repeat motif and scaffold & $\begin{array}{l}\text { Expected size } \\
\text { range (base pairs) }\end{array}$ \\
\hline \multirow[t]{2}{*}{ AF8 } & 1 & F: GGCTTGCAAGTCTAATCTGC & PET & $(A A G)_{16}-2911$ & 178 \\
\hline & & R:TGTGTCTTTGGGATGTATTTCG & & & \\
\hline \multirow[t]{2}{*}{ AF10 } & 1 & F: CGTGCCATCGTAGAACTTCC & 6-FAM & $(\mathrm{TAC})_{10}-2504$ & 274 \\
\hline & & R: GGGACATTGGTAGTACCTTGG & & & \\
\hline \multirow[t]{2}{*}{ AF11 } & 1 & F: GACGGCGGTGTACAGTGATAGT & NED & $(A A G)_{12}-2504$ & 142 \\
\hline & & R: GCAGTAACGCGATTATGCAAGT & & & \\
\hline \multirow[t]{2}{*}{ AF13 } & 1 & F: CGTGTTCCAAGTCAAGTCCA & $\mathrm{VIC}$ & $(\mathrm{CTT})_{9}-1866$ & 136 \\
\hline & & R:TCTCCTTTGCTCCCGTTAGA & & & \\
\hline \multirow[t]{2}{*}{ AF16 } & 2 & F: AGGTCGTGAAGCCGATACTG & 6-FAM & $(\mathrm{TTG})_{10}-2541$ & 179 \\
\hline & & R: CAAAGGCAGATCGAAGGGTA & & & \\
\hline \multirow[t]{2}{*}{ AF48 } & 2 & F:CCACGTTCCACTGTCTCCTT & $\mathrm{VIC}$ & $(A A G)_{12}-2802$ & 352 \\
\hline & & R: GCAAGTCCTCCACTGATGGT & & & \\
\hline \multirow[t]{2}{*}{ AF54 } & 2 & F: GAGAGGTATGCCTTCATGCTTT & VIC & $(\mathrm{ACAT})_{8}-1918$ & 173 \\
\hline & & R: AGTGTGTCGACATGGATTGC & & & \\
\hline \multirow[t]{2}{*}{ AF53 } & 3 & F:TCCTCCAAAGTGACCAAAGC & 6-FAM & $(T C T)_{8}-1918$ & 147 \\
\hline & & R:TGCGATTGCTCAGGACATAG & & & \\
\hline \multirow[t]{2}{*}{ AF55 } & 3 & F:TCATGATCAACCCAGTCCAA & PET & $(\mathrm{GT})_{10^{-1739}}$ & 169 \\
\hline & & R:TGGGCAGAATATCCACGTCT & & & \\
\hline \multirow[t]{2}{*}{ AF64 } & 3 & F: ACTGAGCATTCACCTGCTTG & VIC & $(A C)_{16}-2856$ & 177 \\
\hline & & R: ACCTAGCGGGAGGTTCTAGG & & & \\
\hline \multirow[t]{2}{*}{ AF18 } & 4 & F: CCGCCTCCGAGTGTACTTA & NED & $(\mathrm{TTC})_{29}-1918$ & 198 \\
\hline & & R: CAATAAGGATCGCAATCGTACA & & & \\
\hline \multirow[t]{3}{*}{ AF25 } & 4 & F: GTGAGAGCAATTGGGAAACC & $\mathrm{VIC}$ & $(\mathrm{TAC})_{7}$ & 304 \\
\hline & & & & TCC (TAC)-2504 & \\
\hline & & R:TGACCAATATGCTGGAGGTG & & & \\
\hline \multirow[t]{2}{*}{ AF43 } & 4 & F: GTGAGAGCAATTGGGAAACC & VIC & $(\mathrm{GAG})_{13}-2634$ & 392 \\
\hline & & R:TGACCAATATGCTGGAGGTG & & & \\
\hline
\end{tabular}

\section{Publisher's Note}

Springer Nature remains neutral with regard to jurisdictional claims in published maps and institutional affiliations.

\section{Received: 29 August 2017 Accepted: 11 July 2018}

Published online: 28 July 2018

\section{References}

1. FAO. Worldwide regulations for mycotoxins in food and feed in 2003 . FAO food nutrition paper, Rome, Italy, 81; 2003. p. 1-165.

2. Kimanya M, Meulenaer B, Tiisekwa B, Sigonda M, Devlieghere F, Kolsteren P. Co-occurrence of fumonisins with aflatoxins in home-stored maize for human consumption in rural villages of Tanzania. Risk Assess. 2008;25(11):1353-64

3. Wilson JP, Jurjevic Z, Hanna WW, Wilson DM, Potter TL, Coy AE. Hostspecific variation in infection by toxigenic fungi and contamination by mycotoxins in pearl millet and corn. Mycopathologia. 2006;161(2):101-7.
4. Shephard GS. Chromatographic determination of the fumonisin mycotoxins. J Chromatogr A. 1998;815(1):31-9.

5. Kishore G, Pande KS, Manjula K, Rao JN, Thomas D. Occurrence of mycotoxins and toxigenic fungi in groundnut (Arachis hypogaea L.) seeds in Andhra Pradesh, India. Plant Pathol J. 2002;18(4):204-9.

6. Wogan GN. Present and future directions of translational research on aflatoxin and hepatocellular carcinoma: a review. Food Addit Contam A Chem Anal Control Expo Risk Assess. 2012;29(2):249-57.

7. Wu F. Global impacts of aflatoxin in maize: trade and human health. World Mycotoxin J. 2015;8(2):137-42.

8. Hell K, Fandohan P, Bandyopadhyay R, Kiewnick S, Sikora R, Cotty PJ. Pre- and postharvest management of aflatoxin in maize: an African perspective. In: Leslie JF, Bandyopadhyay R, Visconti A, editors. Mycotoxins detection methods, management, public health and agricultural trade. Oxfordshire: CAB International; 2008. p. 209-18.

9. Krishnamachari K, Nagarajan RV, Bhat R, TilakTBG. Hepatitis due to aflatoxicosis. An outbreak in Western India. Lancet. 1975;305(7915):1061-3.

10. Ngindu A. Outbreak of acute hepatitis caused by aflatoxin poisoning in Kenya. Lancet. 1982;319(8285):1346-8. 
11. Azziz-Baumgartner E. Case-control study of an acute aflatoxicosis outbreak, Kenya, 2004. Environ Health Perspect. 2005;113(12):1779-83.

12. Nyikal J, Misore A, Nzioka C, Njuguna C, Muchiri E, Njau J, Maingi S, Njoroge J, Mutiso J, Onteri J, Langat A, Kilei I, Nyamongo J, Ogana G, Muture B, Tukei P, Onyango C, Ochieng W, Tetteh C, Likimani S, Nguku P, Galgalo T, Kibet S, Manya A, Dahiye A, Mwihia J, Mugoya I, Onsongo J, Ngindu A, DeCock M, Lindblade K, Slutsker L, Amornkul P, Rosen D, Feiken D, Thomas T, Mensah P, Eseko N, Nejjar A, Onsongo M, Kesell F, Njapau H, Park L, Lewis L, Luber G, Rogers H, Backer L, Rubin C, Gieseker E, AzzizBaumgartner E, Chege W, Bowen A. Outbreak of aflatoxin poisoningEastern and Central Provinces, Kenya, January-July 2004. Morb Mortal Wkly Rep. 2004;53(34):790-3.

13. AOAC. Official methods of analysis of AOAC international. Assoc Off Anal Chem Int p. Method ce 2-66; 1999.

14. Pitt J, Hocking A. Fungi and food spoilage. New York: Springer; 2009.

15. Samson RA, Houbraken J, Thrane U, Frisvad JC, Andersen B. Food and indoor fungi; 2010.

16. Kana JR, Gnonlonfin GJB, Harvey J, Wainaina J, Wanjuki I, Skilton RA, Teguia A. Assessment of aflatoxin contamination of maize, peanut meal and poultry feed mixtures from different agroecological zones in Cameroon. Toxins (Basel). 2013;5(5):884-94.

17. Liu K, Muse SV. Powermarker: an integrated analysis environment for genetic marker analysis. Bioinformatics. 2005;21(9):2128-9.

18. Peakall R, Smouse PE. GENALEX 6: genetic analysis in excel. Population genetic software for teaching and research. Mol Ecol Notes. 2006;6(1):288-95.

19. Fandohan P, Zoumenou D, Hounhouigan DJ, Marasas WFO, Wingfield MJ, Hell K. Fate of aflatoxins and fumonisins during the processing of maize into food products in Benin. Int J Food Microbiol. 2005;98(3):249-59.

20. Rahmianna A, Taufiq A, Yusnawan E. Effect of harvest timing and postharvest storage conditions on aflatoxin contamination in groundnuts harvested from the Wonogiri regency in Indonesia. J SAT Agric Res. 2007;5(1):1-3.

21. Sreenivasa MY, Sharmila R, Charith AP, Janardhana GR. Mycological evaluation of maize grains produced in Karnataka (India) for the post harvest fungal contamination. World Appl. Sci J. 2011;13(4):688-92.

22. Kenya MDI. Determination of aflatoxin levels in stored white. Doctoral dissertation, School of Pure and Applied Sciences, Kenyatta University, Kenya; 2004. p. 1-96.

23. Okoth S, Nyongesa B, Ayugi V, Kang E, Korhonen H, Joutsjoki V. Toxigenic potential of aspergillus species occurring on maize kernels from two agro-ecological zones in Kenya; 2012. p. 991-1007.
24. Muthomi J, Mureithi B, Cheminingâ G, Gathumbi J, Mutitu E. Aspergillus species and Aflatoxin b1 in soil, maize grain and flour samples from semiarid and humid regions of Kenya. Int J AgriSci. 2012;2(1):22-34.

25. Hell K, Cardwell F, Setamou M, Poehling HM. The influence of storage practices on aflatoxin contamination in maize in four agroecological zones of Benin, West Africa. J Stored Prod Res. 2000;36(4):365-82.

26. Horn BW, Dorner JW. Soil populations of Aspergillus species from section Flavi along a transect through peanut-growing regions of the United States. Mycologia. 1998;90(5):767-76.

27. Jaime-Garcia R, Cotty PJ. Crop rotation and soil temperature influence the community structure of Aspergillus flavus in soil. Soil Biol Biochem. 2010;42(10):1842-7.

28. Diedhiou P, Bandyopadhyay MR, Atehnkeng J, Ojiambo PS. Aspergillus colonization and aflatoxin contamination of maize and sesame kernels in two agro-ecological zones in Senegal. J Phytopathol. 2011;159(4):268-75.

29. Probst CK, Callicott A, Cotty PJ. Deadly strains of Kenyan Aspergillus are distinct from other aflatoxin producers. Eur J Plant Pathol. 2012;132(3):419-29.

30. Cotty PJ. Aflatoxin-producing potential of communities of Aspergillus section Flavi from cotton producing areas in the United States. Mycol Res. 1997;101(6):698-704.

31. Vaamonde G, Patriarca A, Pinto V, Comerio R, Degrossi C. Variability of aflatoxin and cyclopiazonic acid production by Aspergillus section flavi from different substrates in Argentina. Int J Food Microbiol. 2003:88(1):79-84

32. Bilgrami KS, Choudhary AK. Impact of habitats on toxigenic potential of Aspergillus flavus. J Stored Prod Res. 1993;29(4):351-5.

33. Wambugu S, Kirimi L, Opiyo J. Productivity trends and performance of dairy farming in Kenya. Tegemeo working paper no 43. Tegemeo Inst Agric Policy Dev. 2011;WPS 43/201(i):43.

34. Hell K, Mutegi C. Aflatoxin control and prevention strategies in key crops of Sub-Saharan Africa. Afr J Microbiol Res. 2011;5(5):459-66.

35. Taylor JW, Jacobsen BJ, Kroken S, Kasuga T, Geiser DM, Hibbett DS, Fisher MC. Phylogenetic species recognition and species concepts in fungi. Fungal Genet Biol. 2000;31(1):21-32.

36. Grubisha LC, Cotty PJ. Twenty-four microsatellite markers for the aflatoxinproducing fungus Aspergillus flavus. Mol Ecol Resour. 2009;9(1):264-7.

37. Wang X, Wadl PA, Wood-Jones A, Windham G, Trigiano RN, Scruggs M, Pilgrim C, Baird R. Characterization of expressed sequence tag-derived simple sequence repeat markers for Aspergillus flavus: emphasis on variability of isolates from the southern United States. Mycopathologia. 2012;174(5-6):371-82.
Ready to submit your research? Choose BMC and benefit from:

- fast, convenient online submission

- thorough peer review by experienced researchers in your field

- rapid publication on acceptance

- support for research data, including large and complex data types

- gold Open Access which fosters wider collaboration and increased citations

- maximum visibility for your research: over $100 \mathrm{M}$ website views per year

At BMC, research is always in progress.

Learn more biomedcentral.com/submissions 